\title{
The role of abduction in production of new ideas in design
}

\author{
Koskela, Lauri
}

Springer

2018

Koskela , L , Paavola , S \& Kroll , E 2018, The role of abduction in production of new ideas

in design . in P E Vermaas \& S Vial (eds), Advancements in the Philosophy of Design .

Design Research Foundations , Springer , Cham , pp. 153-183 . https://doi.org/10.1007/978-3-319-73302-9_8

http://hdl.handle.net/10138/325697

https://doi.org/10.1007/978-3-319-73302-9_8

acceptedVersion

Downloaded from Helda, University of Helsinki institutional repository.

This is an electronic reprint of the original article.

This reprint may differ from the original in pagination and typographic detail.

Please cite the original version. 


\title{
The role of abduction in production of new ideas in design
}

\author{
Lauri Koskela ${ }^{1}$, Sami Paavola ${ }^{2}$ and Ehud Kroll ${ }^{3}$
}

A draft of a paper: Koskela, L., Paavola, S., \& Kroll, E. (2018) The role of abduction in production of new ideas in design. In P. E. Vermaas \& S. Vial (Eds.) Advancements in the Philosophy of Design (pp. 153-183). Design Research Foundations. Cham: Springer.

\begin{abstract}
The pragmatist philosopher Peirce insisted that besides deduction and induction there is a third main form of inference, abduction, which is the only type of inference capable of producing new ideas. Also he defined abduction as a stage of the methodological process in science, where hypotheses are formed to explain anomalies. Basing on these seminal ideas, scholars have proposed modified, widened or alternative definitions of abduction and devised taxonomies of abductive inferences. Influenced by Peirce's seminal writings and subsequent treatments on abduction in philosophy of science, design scholars have in the last 40 years endeavoured to shed light on design by means of the concept of abduction. The first treatment was provided by March in 1976. He viewed that abduction, which he called "productive reasoning", is the key mode of reasoning in design. He also presented a three-step cyclic design process, similar to Peirce's methodological process in science. Among the many other later treatments of design abduction, Roozenburg's definition of explanatory and innovative abduction is noteworthy. However, an evaluation of the related literature suggests that research into abduction in design is still in an undeveloped stage. This research shows gaps in coverage, lack of depth and diverging outcomes. By focusing on the differences between science and design as well as on empirical knowledge of different phenomena comprising design, new conceptions of abduction in design are derived. Given the differences of context, abduction in design shows characteristics not yet found or identified in science. For example, abduction can occur in connection to practically all inference types in design; it is a property of an inference besides an inference itself. A number of the most important abductive inference types as they occur in design are identified and discussed in more detail.
\end{abstract}

\footnotetext{
${ }^{1}$ University of Huddersfield, School of Art, Design and Architecture, UK.

2 University of Helsinki, Faculty of Educational Sciences, Finland.

3 ORT Braude College, Dept. of Mechanical Engineering, Israel.
} 


\section{Introduction}

The American pragmatist philosopher C. S. Peirce (1839-1914) developed understanding of an inference type he called abduction throughout his creative research career lasting around 50 years. He used different names in addition to abduction, for example, retroduction and hypothesis, for this inference, and changed his conception of abduction as his research progressed. He viewed abduction as a type of inference that is ubiquitously used in everyday life by humans - sometimes comparing abductive innate tendency of humans to instincts by animals, for example, to chickens having an innate tendency of finding proper food and eating (Peirce CP 5.591, 1903). However, it is the role of abduction in science that Peirce's interest was especially focused on. Abduction was conceived by him as the type of inference through which all new ideas, still hypothetical, are produced in science. It starts when something surprising has been observed, requiring explanation. It was characterized by Peirce as the third type of inference, besides deduction and induction.

Although the concept of abduction stems from the latter part of the $19^{\text {th }}$ century, it was only in the latter part of the $20^{\text {th }}$ century that it started to be discussed again, especially in philosophy of science but also in other fields. This discussion has taken different directions. Based on the original ideas of Peirce, scholars have proposed modified, widened or alternative definitions of abduction and devised taxonomies of abductive inferences. Also, later authors have endeavoured to reach a better understanding of Peirce's original ideas. Nevertheless, Hintikka (1999) holds the problem of abduction as the most important question in epistemology.

Inspired by treatments of abduction especially in philosophy of science, there is a broadening interest in analyzing design in terms of abduction. However, in critical examination, it can be asked whether this work has led to conceptual gains in design science or to useful advances in design practice.

Why has the progress of clarifying abduction in design been slow? Three main problems can be recognized, namely lacking maturity of the concept of abduction in philosophy of science, the differences in context between the two fields, and the embryonic state of the science of design. As different authors in the design field pick up different conceptions of abduction from the wider literature, the discussion has tended to be fragmented and has hardly led to cumulative increase in understanding. The concept of abduction is still deeply embedded in specific interpretations within the context of science, where the 
question is about suggesting a cause (i.e. explanation) for a surprising phenomenon. In design, similarly a "cause" for the required behavior is searched, but design may comprise also other types of inferences through which a new idea can emerge. Unfortunately, there has been little scholarly work on the different types of design inferences. Indeed, many theories of design conflate types and chains of creative inferences under the term "synthesis".

Thus the question remains: how do new ideas emerge in design, and how, if at all, abduction can help in analyzing these processes? In view of this, this paper attempts to clarify the phenomenon of abduction in design. The main starting point is that the concept of abduction, as it has been discussed in philosophy of science, carries implicit contextual assumptions, which are not compatible with the context of design. We contend that the focus should be directed, besides the concept of abduction, to the underlying phenomena and their context as they occur in design. In this way, it will be possible to define and characterise abductive inferences in design.

The paper is structured as follows. In the next section, an overview on the prior research on abduction is given. It should be noted that the conceptions of abduction have developed over time, and are about to be developed further. We aim at giving a short picture of a variety of interpretations on abduction. Then, a survey of prior research on abduction in design is presented as well as a critical evaluation of it. In the following section, the newly-developed understanding of abduction in design is presented, and a number of main types of abductive inferences in design are introduced. A section on conclusions, including further research needs, completes the paper.

\section{Abduction in philosophy of science}

\subsection{Origin of the concept of abduction: Peirce}

Throughout his career Peirce insisted that besides deduction and induction there is a third main form of inference (see e.g. Peirce W $1: 180,1865$; CP 8:385-388, 1913). But there were changes in his notions and formulations of abduction over the years while he interpreted it in relationship to various questions concerning reasoning, inquiry and human cognition (Paavola 2012, 46-47). It is customary to discern two main phases in Peirce's treatment of abduction (Fann 1970). In his early works Peirce defined abduction as an evidencing process by using syllogistic formulations. Typical examples of abduction and induction can be formulated by inverting a deductive syllogism in two different ways. Abduction is an inference of 
a cause from its effects (W 1:180,1865), or "reasoning from consequent to antecedent (CP 5.276, 1868), or "making an hypothesis" (CP 2.623, 1878). This is different than induction, which is typically about generalising and inferring a rule on the basis of cases (CP 2.622-624, 1878). In these early formulations, the strength of abductive arguments was presented quite vaguely. Peirce said that abduction (or 'hypothesis' as he then called it) is a "weak kind of argument", and about surmising (CP 2.625, 1878), but in his early works he often presented it also as a form of probable reasoning (e.g. CP 2.511, 1867).

In his later works Peirce emphasised abduction as a part of a methodological process (Fann 1970). A basic formulation on abduction is often cited (see Peirce, CP 5.189; Hanson 1958, 86):

The surprising fact, $\mathrm{C}$, is observed;

But if A [an explanatory hypothesis] were true, $\mathrm{C}$ would be a matter of course,

Hence, there is reason to suspect that $\mathrm{A}$ is true.

Here abduction is a part of a process of inquiry and central in that stage where hypotheses are invented on the basis of anomalies or clues ("the surprising fact"). Abduction provides only tentative conclusions ("there is reason to suspect"). Besides abduction, the process of inquiry essentially needs deduction (which is important when hypotheses are explicated) and induction (which is central for testing these hypotheses). These three (abduction, deduction, induction) provide the basic phases of the process of inquiry (CP 6.469-473, 1908), and the role of induction is then different compared to Peirce's early formulations (this difference will be further discussed in section 3.3).

Peirce emphasised in his later works more the weakness of abduction: "Deduction proves that something must be; Induction shows that something actually is operative; Abduction merely suggests that something may be" (CP 5.171, 1903). Peirce also insisted now that human beings must have a guessing instinct for finding fertile hypotheses (CP 7.220, 1901). In his early formulations Peirce had rejected the connection of abduction (or reasoning in general) to instinct (CP 2.749-754, 1883), but in his later works a guessing instinct is precisely the root of abduction (CP 8.234, c. 1910), perhaps somewhat paradoxically, because he emphasised now that abduction is a weak form of inference. Peirce had, however, different kinds of formulations on abduction, maintaining, for example, that it is close to perceptual judgment and an "act of insight" (CP 5.181, 1903), an "inference through an icon" (Peirce CP 2.96, c. 1902), or a first starting of a hypothesis as a simple interrogation (Peirce CP 6.524, 1901). One 
central feature of abduction is that it is a way of arranging facts in a new way (Peirce, PPM 282-283, 1903):

A mass of facts is before us. We go through them. We examine them. We find them a confused snarl, an impenetrable jungle. We are unable to hold them in our minds. We endeavor to set them down upon paper; but they seem so multiplex intricate that we can neither satisfy ourselves that what we have set down represents the facts, nor can we get any clear idea of what it is that we have set down. But suddenly, while we are poring over our digest of the facts and are endeavoring to set them into order, it occurs to us that if we were to assume something to be true that we do not know to be true, these facts would arrange themselves luminously. That is abduction.

There are many predecessors and earlier, close formulations to Peirce's conception of abduction (see Paavola 2012, 21-22). Peirce himself referred to earlier writers who had used the term "hypothesis" in a sense of "the conclusion of an argument from consequence and consequent to antecedent" (see EP 1:34-35, note, 1868). Clear influences were also Aristotelean syllogisms and Kantian philosophy. Especially in his early lectures Peirce also analysed the "logic of science" by his contemporaries like Whewell, Mill and Comte (see Peirce W 1: 205-223, 1865). Peirce appreciated especially Whewell's work (W 1:211, 1865) and there are interesting, later discussions on similarities and differences between Peirce's and Whewell's conceptions of the logic of science (Snyder 1997; Niiniluoto 1999a). Regarding Aristotelean syllogisms, Peirce even speculated that Aristotle had been formulating the basics of abduction in Prior Analytics with the notion of 'apagoge', but this sense had been lost because the text of Aristotle had been misunderstood and mistranslated as a consequence of having been corrupted (CP 1.65, c. 1896). Later he emphasised that this theory on the (mis)interpretation of Aristotle was doubtful and only conjectural (CP 8.209, c. 1905). There are, however, interesting recent interpretations maintaining that there are abductive syllogisms present in Aristotle's work but in places that Peirce neglected. Abduction comes close to 'anchinoia', which is for Aristotle a skill of conjecture or sagacity discovering or inferring a cause (Florez 2014). One interesting parallel to Peirce's abduction (especially when interpreted as a regressive inference of a cause from its effects) is the method of analysis (where regressive inferences also play a central part) and synthesis by Greek geometers, which is often referred to and applied as heuristics in the history of science (Niiniluoto 1999b). This topic will be taken up in section 3 . 


\subsection{Later understandings of abduction}

Abduction was for long quite marginally treated (Paavola 2012, 31-45). There were a number of reasons for that. Peirce's philosophy in general was not much studied. The $20^{\text {th }}$-century philosophers of science (like Popper and Hempel) were mostly against any logical treatments of the area of discovery. Abduction was then seen as conflating discovery and justification, as defined by Reichenbach (1938), and either being a form of induction, or close to the hypothetico-deductive model of science. A notable exception was Hanson (1958) who defended Peirce's "logic of discovery" as a means of conceptualising what is the key issue in science, that is, the search for new hypotheses. But it was not until the late 1970s and early 1980s that abduction started to raise a broader interest, especially in philosophy of science and in methodology (Nickles 1980; Eco and Sebeok 1983). Besides Peircean tradition, abduction is nowadays influenced also by the "Inference to the Best Explanation" (IBE) model that was formulated by Harman in the late 1960s (Harman 1965; 1968). IBE is close to Peirce's formulations on abduction although there are also clear differences (Minnameier 2004; Paavola 2006).

Nowadays the uses and discussions on abduction have expanded on various fields of research, such as logic, philosophy of science, research methodology, semiotics, cognitive sciences, artificial intelligence and diagnostics. It is then no wonder that there are different emphases and interpretations of abduction. This might cause confusion but is also a strength when formulations of abduction are developed further.

Different kinds of distinctions and taxonomies on various forms of abduction have been suggested. One distinction is if abduction is supposed to be a way of generating new hypotheses ("creative abduction"), or a way of evaluating and choosing a candidate from given options ("selective abduction") (Schurz 2008; cf. Magnani 2001; Eco 1983). Another basic distinction is if the abduced conclusion is a singular fact, law, or theory (or a theoretical model) (Schurz 2008). Still another dimension is what triggers abductive reasoning: a novelty or an anomaly, or perhaps just a phenomenon to be explained (see Aliseda 2006, 45). Schurz (2008) presents a thorough classification of abduction patterns, all of which are "special patterns of inference to the best explanation”. Based on Schurz' classification, Hoffman (2010) develops a taxonomy of 15 forms of abductive inference.

Abduction is usually connected to searching for explanatory hypotheses. However, according to Gabbay and Woods (2005) abduction is not necessarily tied to explanation, but the characteristic of abduction is that it is "ignorance-preserving" reasoning, in contrast 
to deduction as "truth-preserving" and induction as "probabilityenhancing". Furthermore, abduction can also be interpreted: more clearly as a form of reasoning; or more closely related to such cognitive issues as perception, guessing and insights; or as a part of a broader process of inquiry (Paavola and Hakkarainen 2005).

\section{Abduction in design}

\subsection{Prior treatments of abduction in design}

March (1976) suggests that abduction, which he calls "productive reasoning", is the key mode of reasoning in design. He also points to the confusion and misunderstanding created by not distinguishing between scientific and design hypotheses, and between logical propositions and design proposals. Whereas the goal of science is to establish general laws, he says, design is concerned with realising a particular outcome. The pattern of abduction proposed by March is: from certain characteristics that are sought, and on the basis of previous knowledge and models of possibilities, a design proposal is put forward. March presents a three-step cyclic design process that is similar to Peirce's three modes of reasoning (abduction-deductioninduction), and says that rational designing has three tasks:

1. Creating a novel composition (i.e., the artefact) as the outcome (the 'case') of productive (=abductive) reasoning,

2. Predicting the performance characteristics of the artefact by deduction,

3. Accumulating habitual notions and established values by induction.

Induction, therefore, may have two related roles: a background activity that represents ongoing acquisition of experience and expertise, and an evaluative step in the design cycles.

Goel (1988) proposes to extend and complicate March's productiondeduction-induction model if we wish to use it in knowledge-based systems. He maintains that it is too simplistic to divide the phases of design activity into three categories. His argument is based on the fact that the laws (also called rules or knowledge) can have different logical natures: some are universal, others statistical, and a third category is the quasi-laws that govern the behaviour of complex adaptive systems such as humans and organisations. Depending on the type of law involved, the prediction of performance may no longer be a deductive inference, and the inference of design descriptions, while still 
abductive, poses new problems related to affirming the consequent and to instantiating an individual.

Takeda et al. (1990) propose a cognitive model of the design process based on general design theory (GDT), which contains three types of reasoning: deduction, abduction and circumscription. Circumscription is used to find exceptions that cause a contradiction, so the incomplete knowledge of object properties and behaviours at any time during the design process can be modified. The design process consists of a 5-step cycle: (1) identification of problems by comparing the designed object with the required specifications, (2) suggestion of key concepts to solve the problems, (3) development of candidate solutions from the key concepts and design knowledge, (4) evaluation to confirm the candidate solutions, and (5) conclusion to decide which candidate to adopt. Step (1) is carried out by circumscription, step (2) by abduction, and steps (3) and (4) by deduction. Step (5) is a decision-making process that is not analysed with the logical framework. Step (2), the abductive step, basically follows the paradigm: from the properties of the current design candidate and the knowledge of object properties and behaviour available at the current state, obtain a description of the current design candidate. In this sense, it is similar to the "standard" syllogism of "given fact + major premise $\rightarrow$ conclusion".

Takeda (1994) continues this work, but emphasises the role of abduction as the ampliative process of making integrated hypotheses and theories. He claims that Peirce's abduction is unattractive in design because it only enumerates many hypotheses. In contrast, design abduction is different because it not only generates hypotheses (descriptions of objects), but also considers the background theory and uses part of it, the "explanatory theory", by selecting relevant rules and laws and even generating new ones. Takeda's view on design abduction is therefore a step in the direction of Roozenburg's innovative abduction (see below).

The design support system proposed by Takeda et al. (2003) is based on a model of the design process that consists of iterations of abduction (to create a new idea or artifact) and deduction (to validate the design). They claim that creative design must contain two aspects: generating a new product and expansion of knowledge. Abduction should include more types of reasoning then Peirce's "abduction as inversed deduction", which is merely one category of factual abduction. It should include also discovery of new laws. Factual abduction is used to create a new design while law abduction creates a new theory. Both abductions take place concurrently to achieve "integration of knowledge". Among the several methods that can be used for law abduction (some of which are mentioned by Schurz (2008)), they focus 
on analogical inference. The procedure for carrying out the analogical abduction starts by choosing a candidate theory (i.e., knowledge base), preferably one with low similarity to the original knowledge in order to increase the likelihood of a surprising result. Next, correspondences are created among concepts in the chosen theories, followed by generation of candidate design knowledge, which are the hypotheses found appropriate to solve the current design problem. Finally, candidate design solutions are created from the new integrated knowledge by a process of hypothesis verification.

Tomiyama et al. (2003) connect the above work even more strongly with Schurz's classification. They claim that Schurz's first order existential abduction (one type of his factual abductions) can generate a design that performs given requirements, but because both the requirements and rules are known, no creative design can result. Another important type is theoretical-fact abduction that generates new initial or boundary conditions that apply to the yet-unknown design solution. This abduction does not generate solutions, but conditions that the solution should satisfy. These conditions can become new design sub-problems or additional requirements. A third type of abduction is a combination of modes of Schurz's second order existential abduction, and plays a role in integrating multiple theories. This "abduction for integration" consists of identifying the applicability and domain of seemingly irrelevant theories (as in analogical reasoning) and merging them with the existing knowledge.

Roozenburg (1993) discusses in depth the question whether the reasoning towards a tentative description of a design with plausible reasoning follows the conventional view on abduction, or whether it should be defined differently. He argues that the commonly presented view, especially in artificial intelligence literature, deals with "explanatory" abductions, which are good for diagnosis or troubleshooting, but that the core of design reasoning follows another type of abduction, for which he proposes the terms "innovative" abduction and "innoduction" (Roozenburg and Eekels, 1995). In fact, says Roozenburg (1993), Habermas (1978) distinguished between explanatory abduction and innovative abduction, and it was March who did not make that distinction. In the case of innovative abduction, says Roosenburg, "Starting from a surprising, not yet explainable fact (the result), we try to conceive of a new rule (a principle, law, or theory) that allows us to infer the cause (the case); the rule itself, therefore, is not yet assumed to be true". He goes on explaining that the conclusion of this inference is a hypothesis that still needs to be tested by deduction and induction before it becomes a new rule with explaining power. Roozenburg's pattern of innovative abduction is therefore: 


$$
\begin{array}{ll}
q & (q \text { is a given fact, a desired result }) \\
p \rightarrow q & \text { (a rule to be inferred first, IF } p \text { THEN } q) \\
p & (p \text { is the conclusion, the cause, that immediately follows })
\end{array}
$$

He even says that the above pattern is Peirce's original intention, because $p$ cannot be part of the premise and needs to be part of the conclusion of the inference (cf. CP 5.189, 1903). This means that both $p$ $\rightarrow q$ and $p$ 'present' themselves together, at the same moment.

Roozenburg's innovative abduction is claimed to represent the kernel of the design process. The desired result is the function to be accomplished, his rule follows the formula "if form + way of use then function", and the conclusion is form + way of use.

Dorst (2011) proposes another view on design abduction that revolves around the following formula:

what (the artefact) + how (the working principle) $\rightarrow$ value (aspired)

in which the (aspired) value is always given. If the how is also given, then the what is generated by a so-called abduction-1, which is precisely "explanatory" abduction. Dorst calls this case "conventional ('closed') problem-solving that designers often do". If, however, the how is not given, then we have a more 'open' problem in which we need to decide on both the working principle and the artefact. This is accomplished by abduction-2, which is the same as Roozenburg's innovative abduction. Abduction-2 is carried out by first developing or adopting a 'frame' (after Schön), which is a "general implication that by applying a certain working principle we will create a specific value". The framing activity is characterised by Dorst as being "a form of induction", because it is reasoning back from consequences (this is in conflict with Peirce to whom that kind of reasoning represents abduction). With the help of framing, abduction-2 takes place according to the following pattern:

$$
\begin{array}{ll}
q & (q \text { is the given desired value }) \\
-\begin{array}{l}
q \rightarrow q \\
p
\end{array} & \text { (IF how } \text { THEN value, the first conclusion) }
\end{array}
$$

When a possible or promising frame has been proposed and the how is known, says Dorst, abduction- 1 can take place to design the what, the artefact. 
Kolko (2010) defines design synthesis as an abductive sensemaking process of manipulating, organizing, pruning and filtering data related to the design problem in order to produce information and knowledge. Three methods of formalising the synthesis process are proposed: reframing, concept mapping and insight combination. Each of the methods emphasises actions of prioritising, judging and forging connections, which are claimed to have been derived directly from the logical processes of abduction and the cognitive psychology theory of sensemaking. However, the connection of these actions to abductive reasoning seems rather loose, and is mostly based on Kolko's claim that abduction (defined as IBE) is the only type of inference that can generate something new, and that it involves intuition and the designer's own life experiences.

Lu and Liu (2012) refer to Peirce's description of abduction as "intelligent guessing" and show how abductive reasoning can be applied in three different ways to design synthesis: (1) inferring functional requirements from the customer's need, (2) deriving design concepts from the requirements, and (3) diagnosing faults within design concepts to facilitate the selection among them. Using Schurz's classification, Lu and Liu associate these three types with second order existential abduction, factual or law abduction, and observable-fact abduction, respectively.

Ullah et al. (2012) attempt to connect the notion of "classical abduction" to the $\mathrm{C}-\mathrm{K}$ theory of design. They conclude that conceiving a creative ("undecided" relative to existing knowledge) concept is more complex than abduction, being a motivation-driven process. Motivation here consists of a "compelling reason"-why a certain concept is pursued, and an "epistemic challenge" — seeking new knowledge.

Pauwels and Bod (2014) adopt Peirce's model of scientific inquiry, claiming that it (and design) consists of repetitive cycles of abduction (to make hypotheses and interpretations of "the world" or "the situation"), deduction (to make predictions of anticipated consequences), and induction (to devise experiments to test the anticipated consequences and to learn new knowledge). Abduction is identified here with analogical thinking and the design cycle is demonstrated through an example of a kitchen sketching episode. It starts with the designer looking at a partial sketch and trying to find an explanation (analogy, interpretation, idea) to it by abduction. The abduction results in a hypothesis that a specific other configuration might improve the design. Now, from this hypothesis, the designer deduces a specific prediction about what to do next, resulting in consequences: re-arranging the sketch lines so that the kitchen will 
improve. Finally, an induction step is used to verify that the new design has indeed been improved, and this step constitutes learning.

More recently, a need-function-principle-system (NFPS) model has been proposed for conceptual design (Chen et al. 2015a; 2015b). A clarification stage converts subjective needs into objective functions, followed by a synthesis stage to find abstract principles for satisfying the functions. The abstract principles consist of combinations of action classes and behaviour classes, which are generalised actions and behaviours, respectively. Next comes an embodiment stage, where action classes and behaviour classes are instantiated as a system (i.e., structure) having corresponding specific actions and behaviours. The actions and behaviours are verified in an analysis stage, followed by a prediction stage to identify unintended side effects and possibly generate new functions for the next design cycle. Both synthesis and development stages are claimed to be "implicit abductions" or innoductions, because they lack sufficient premises for generating only one result.

An empirical approach to study abduction in design is demonstrated by Cramer-Petersen and Ahmed-Kristensen (2015). They define abduction as the use of a known principle, law or theory for the purpose of a causal explanation, and investigate aspects of idea-generation sessions by protocol analyses. Abductive reasoning is identified by the use of the following "indicator words": could, maybe, think, could be, imagine, probably, likely; deductive by so, then, therefore, that is, must be, as, can; and induction is correlated with $I, m e$, you, they, we, them. They found that abduction was the least frequent type of reasoning in the protocols, although most ideas were initiated by it. The explanation was that abduction only requires a few statements to hypothesise and introduce new frames of understanding the problem. Similarly, the high proportion of deductive reasoning was explained by observing that deduction often comes in series of several statements about the structure of an idea. Inductive reasoning was found to occur more frequently than abductive reasoning, but its occurrences rarely happened at the beginning of idea-generation episodes. They also found that abductive reasoning led to more radical ideas, whereas deductive reasoning led to ideas related to project requirements (especially cost reduction). The latter type had a higher proportion being rejected as not valuable.

\subsection{Critical evaluation of prior treatments of abduction in design}

The previous section has made it clear that there is a variety of interpretations of abduction in design. They do not provide a unified picture of abduction. In this section, the prior treatments of abduction 
in design are analyzed and critically evaluated. The discussion is structured according to the main topics arising from the materials examined.

\subsubsection{Lacking interest and contribution by philosophers and logicians}

It is striking that understanding on design abduction has exclusively been advanced by scholars in the design domain. Professional philosophers have shown little interest in the clarification of abduction in design. This is further exemplified by the fact that the authoritative and thorough handbook Philosophy of technology and engineering sciences (Gabbay et al. 2009) has "deductive reasoning" in its index, but nothing on abduction. Unfortunately, the inevitable academic division of work has implied that the studies of design scholars on abduction tend to be thin on the side of philosophy of science and logic. There have been basic misunderstandings in the interpretation of literature in philosophy of science.

\subsubsection{Fragmentation and divergence}

The existence of various somewhat different characterizations of abduction already by Peirce and the lack of unity in philosophy of science regarding abduction has led to a situation where design scholars have picked up somewhat varying concepts and interpretations of abduction and often developed them into new directions. It seems that this reflects partially the breadth of discussion within the area of design, and also of abduction. Arguably, however, this situation has tended to lead to fragmentation of discussion, lacking accumulation of understanding and divergence on views on abduction.

\subsubsection{Methodological issues}

Most research into design abduction is conceptual, driven by the pursuit of adoption and adaption of abduction concepts from science to design. The developed design abduction concepts are illustrated-or perhaps initially justified-through schematic or worked examples. Empirical research on abduction in general has been scarce (cf. Cramer-Petersen \& Ahmed-Kristensen 2015; Dunne \& Dougherty 2016).

\subsubsection{Contextual differences between science and design}

Although the contextual differences between science and design were discussed already in the seminal contribution by March (1976), it is doubtful whether they have been fully covered in design abduction research. In the following, the topics arising from such differences are discussed. 


\subsubsection{Starting point for abduction}

In the accounts on science, there is usually a focal point, surprising observation or anomaly, that forms a starting point for abduction. Based on this, singular (and often celebrated) acts of abduction have been addressed in discussions on abduction in science (for example, Hanson 1958). However, as Hanson himself pointed out, discovery processes often extend over longer time periods (ibid.) and clearly involve several mixed forms of reasoning. In treatments on abduction in design, the focus similarly has been on singular abduction from the problem to the solution, usually from function to structure. However, the design counterpart for surprising observations in science has hardly been discussed and characterized.

Another question hardly discussed is related to the location of abduction in the respective process. In science, abduction is located next to the surprising observation, in the beginning of the research cycle. This is in connection to the situation where in science typically one aspect or part of a phenomenon is explained (Eekels and Roozenburg 1991). However, in design, the totality of the targeted artefact is designed. This implies that in design, a problematic situation (requiring an abductive solution) may occur in any part of the design process, not only at its start, and that there may be many different problems in the framework of a design cycle.

\subsubsection{The abductive inference}

The approaches to design abduction have not always been sensitive to differences in the type of inference in science and design. March (1976) explained that abduction in science is about generalisation, whereas in design it is about particularisation. However, the situation in design (and as a matter of fact, also in science) is more nuanced. Often also in design, the first step is to find an (abstract) natural law or fundamental concept, from which the form and structure of the artefact is abducted. Thus, abductions in both ways, generalisation and particularisation, occur in design.

Another question is that in the classical treatment of abduction in science, the inference is a regressive one, from effect to cause. This idea has largely been accepted also for design abduction. However, there are other types of problems in design, say decomposition of functions, physical composition of the artefact or finding the most suitable framing for a design problem. Whether ampliative solutions to these should be viewed as types of abduction has not been discussed. 


\subsubsection{Relation of abduction to other forms of inferences in science and design}

The Peircean definition of abduction as a third form of reasoning, besides deduction and induction, is adopted by authors on design abduction. However, the relation of abduction to other forms of reasoning and mixed forms of reasoning in design tend to remain vague as there is little scholarly consensus on reasoning types in design. Also, that Peirce, in his later works, defines induction in a non-conventional manner has not been discussed in design abduction literature. The question whether all regressive inferences in design are identified as abduction remains without substantive discussion.

\subsubsection{Outcome of abduction}

In science, the outcome of abduction is hypothetical. In design, the same applies as more or less all intermediate outcomes are hypothetical until the final validation. However, in design there are additional criteria. The embodiment design stage can embrace only such forms, materials and assemblies that can be realised in the purported context. These have not been discussed in prior treatments.

\subsubsection{Context for novelty}

In science the context of abduction, at least in the end, is the whole scientific community interested in the topic in question. Thus, novelty depends on what is known by the community. In design, it is rather an individual designer or a design team, who provide the context for abduction. Novelty is thus relative to what is known by the designer or a design team. This issue has hardly been discussed in the literature on design abduction.

\subsubsection{Design creativity}

The literature on abduction in design makes little reference to the literature on design creativity, although the subject matter in these two fields seems highly overlapping, namely emergence of novelty.

\subsection{Reflections on abduction: Potential problems in Peirce's conception of abduction}

The difficulties of conceiving the form and role of abduction in design, as discussed above, seem to derive, at least partly, from the specific features of Peirce's treatment of abduction and gaps in its subsequent 
interpretations ${ }^{4}$. Such problems are especially related to using only the logical scheme of syllogism as the starting point, the position of induction in relation to abduction, and the relation of abduction to regressive inferences as they occur in the method of analysis.

Peirce started his research on abduction by using the syllogistic approach to logic, originated by Aristotle, to illustrate the differences between deduction, induction and abduction. Syllogisms had been the dominant approach in logic for several centuries till the mid 19th century, when new approaches started to be developed (actually Peirce was among the initiators of these). A syllogism is an inference from two premises, both containing a "middle term" that thus connects them, towards a conclusion (Lagerlund 2016). The problem with the syllogistic conception of an abductive inference is that the new idea seems already to be in the premises of the inference instead of being created through that inference ${ }^{5}$ (see section 3.1 ). The syllogistic conception thus seems to compromise the central notion of abduction engendering a new idea. It might be one reason for Peirce to adopt the broader view of abduction as a stage in the research process (Psillos 2009).

The existence of these two Peircean conceptions of abduction (as an inference and as a stage in a research process), and also the discussions on the nature of the syllogistic presentation of abduction have been confusing. It seems this was the reason for Habermas (1978) coining the terms explanatory abduction and innovative abduction, based on which Roozenburg (1993) saw it necessary to invent the term "innoduction", innovative abduction. However, as he himself admits, this kind of abduction is what Peirce may have had in mind. Thus, the necessity of a new name for it can be questioned.

\footnotetext{
${ }^{4}$ Recent developments of abduction in philosophy of science highlight broader and more dynamic understanding of this concept but they have not yet had impact on the research on abduction in design.

5 Psillos (2009) states on this: "This creates a certain tension in Peirce's account. Hypothesis is ampliative and the sole generator of new ideas or content. And yet, in the syllogistic conception of hypothetic inference, the new ideas or content must already be there before they are accepted as the conclusion of the inference." However, this commonly presented view can be debated. Verene (2008) has argued that Aristotle's theory of syllogisms was actually twofold: a syllogism serves both as an instrument of demonstration and as a means for the generation of new ideas. Thus (Verene 1980): "The invention of an argument requires the invention of the middle term of the syllogism. The creation of the middle term and the needed premises are aspects of a common process; they come into being at the same time." If we subscribe to the conception of syllogisms as advanced by Verene, the tension alleged by Psillos disappears (see also Paavola 2004).
} 
Another source of confusion is related to induction. In the early writings of Peirce, induction was about generalisation of a rule from a sample, corresponding to the still common usage of this term. However, in his later work, the meaning of induction switched to confirmation of an abductive hypothesis through experimental verification ${ }^{6}$. Both in the earlier and later conception by Peirce, abduction was related to deduction and induction; however, the meaning of induction is very different in these two cases.

Based on the conception of Peirce of the scientific process as abductiondeduction-induction, March (1976) presents a tripartite model of design, consisting of the corresponding stages of production, deduction and induction. However, when trying to fit design into the mold provided by science, he mistakenly-so it seems to us-describes the last stage as follows: "the design and its expected characteristics are used to infer new generalisations". In our view, the evaluation stage in design is occupied by the question whether the design fulfills the requirements of the particular situation; it is not primarily about the generalisation. Also Pauwels and Bod (2014) similarly adopt the tripartite model of Peirce, and call the evaluation stage in the architectural process induction.

The third source of confusion is the question how abduction relates to regressive inferences as they occur in the stage of analysis in the context of the geometrical method of analysis (Hintikka and Remes 1974). This method has been influential in science; no less figure than Newton (2003) writes on analysis in Opticks: "By this way of Analysis we may proceed from Compounds to Ingredients, from Motions to the Forces producing them; in general, from Effects to their Causes, ...". During the active years of Peirce, the method of analysis was adopted as the scientific model by several leading scientists and philosophers of science, such as Duhamel, Whewell and Mach. As argued by Koskela et al. (2014), analysis proceeds through regressive inferences (but also through decomposition and transformation), whereas synthesis, being an inverse of analysis, proceeds through deduction and composition. Peirce ${ }^{7}$ did not relate abduction to the method of analysis. Intriguingly,

\footnotetext{
6 It is noteworthy that Hintikka (2007, p. 55) advises not to use the word induction in the case of hypothesis testing: "[...] I do not think that it is instructive to call such reasoning inductive, but this is a merely terminological matter". Indeed, if the meaning of the term induction is changed in the way Peirce does, the question emerges how should the types of reasoning traditionally referred to as induction be called.

${ }^{7}$ Actually it is not clear whether he was aware of the method of analysis in the first place. In one instance, he wrote about analysis and synthesis as used in science: "This method of procedure is that Analytic Method to which modern physics owes all its triumphs." (Feibleman 1969). However, from the context it emerges that he is not
} 
the method of analysis has been proposed also as a model of design since Aristotle (Koskela et al. 2014).

Now, analysis would seem to serve the same function as abductionproceeding from effects to causes-but the question arises whether we should equate all regressive inferences ${ }^{8}$ with abductive inferences, especially in the case that a regressive inference is not providing a new idea. Note that as Peirce's viewpoint is the syllogism, he is typically discussing one inference, whereas in analysis it is customary to acknowledge a chain of regressive inferences (for example, in Aristotle's account in Nicomachean Ethics), some of which may be habitual, some selective and some creative. This boils down to the question whether abduction should be understood as a type of inference (that is, regressive inference as in the method of analysis) or a property of an inference (that is, any inference producing a new idea). Our view is that the distinguishing characteristic of abduction is the generation of new ideas ${ }^{9}$. In this way, it will be possible to enrich the conceptualisation of design with a new distinction. However, as evident from the presentation on prior views on abduction especially in the design domain, the term abduction is sometimes understood to also cover regressive inferences that do not yield novelty ${ }^{10}$. This terminological issue cannot be solved in this presentation; for communicative purposes, we use the noun "abduction" as it is generally understood in the Peircean sense, to denote a regressive inference producing a new idea, while the adjective "abductive" is used to refer to a property of an inference, namely that a new idea has been engendered.

\footnotetext{
discussing the method of analysis from geometry but differential calculus (also called analysis). Even more strangely, he compares analysis, in this same sense of differential calculus, to Hegel's method of analysis and synthesis (Feibleman 1969). These failures to discuss the method of analysis, when it would have been apt and deserved, would be understandable if he was not aware of the method of analysis.

${ }^{8}$ Peckhaus (2002) characterises regressive analysis in terms that could be used for abduction as well: "...regressive analysis is not completely logically determined, but has elements of contingency, creativity and intuition".

${ }^{9}$ Thus, we tend to agree with Pietarinen (2014): "Another way of putting a related point across is to observe that, taking retroduction only as a converse of deduction, or simply as reasoning from effects to causes, or from the major premiss and the conclusion to the minor premiss, is a limiting view of retroduction."

${ }^{10}$ For example, abduction-1 as defined by Dorst (2011).
} 


\section{Towards defining abduction in design}

\subsection{How should we define abduction in design?}

Why to define and clarify abduction in design? While a major part of designing is based on habitual solutions and generally available knowledge, there is also a need for novelty, new ideas, through which better design outcomes can be targeted. The existing theories of design do not provide a systematic and detailed account on how new ideas emerge in the design process. Fundamental understanding on this crucial part of design has thus been lacking. Here, we aim at a descriptive account of abduction in design. Often, prescriptive methods evolve based on descriptive theories (Kroll 2013), and thus it may be possible, as a next step, to start developing a method providing a prescription for innovative design.

In the following, a framework for conceptualising abduction in design is presented. It is based on two main starting points discussed in the preceding sections: (1) abduction is about introducing new ideas into the situation ${ }^{11}$; (2) abduction is a property of an inference besides an inference type as such. The first feature is of course directly coming from Peirce. Regarding the second, the common interpretation of Peirce is that it is an inference type. However, through accepting abduction (or abduction-like inference) happening by a mixture with induction (in the case of analogy) or deduction (in the case of theorematic reasoning), he de facto gave support to the idea that it is a property of an inference. The implications of this second starting point are summarized in section 4.1.3.

We recognise the following important dimensions of abduction in design: triggering factor, position in the process, nature of the abductive inference, outcome of the abductive inference, and psychological character of abduction. In the following, these are presented in more detail and also in relation to understanding of abduction in scientific research. Based on these considerations, we then present the most common types of abduction in design.

\footnotetext{
${ }^{11}$ Here we follow the intepretation of Suwa et al. (2000), according to which it is situated invention (interpreted here as situational novelty) that occurs in design, in contrast to historical invention (first time in history) and psychological invention (first time for the person in question), concepts defined by Boden (1996). Note that in science, historical inventions are targeted; nevertheless, these will emerge only through psychological invention.
} 


\subsubsection{Triggering factor: abductive problem}

Taking lead from Velázquez-Quesada et al. (2013), we propose that abduction is typically triggered by an abductive problem. In science, the search for fertile problems and their formulations often start the process. A surprising observation (Peirce) or an anomaly (Kuhn) provide a basis for such a problem. In design, we define abductive problem as one that the designer is not capable of solving using habitual or (generally) known solutions. This notion of abductive problem is relative, depending on the knowledge and experience of the designer or design team in question. An abductive problem does not necessarily lead to abduction; for example, if a solution can be found directly, in a non-abductive way from literature or from more experienced colleagues ${ }^{12}$. On the other hand, abduction may occur without a preceding abductive problem (this will be discussed below).

It is noteworthy that an abductive problem may be deliberately created through stretch targets (Thompson \& al. 1997): create a new product that is, say, $10 \%$ better in performance than the best current corresponding products.

\subsubsection{Position in the process: anywhere}

In typical formulations of abduction in science, a surprising observation motivates and initiates the inquiry process. Thus, abduction is positioned at the start of the process. A design process is often complex and covers a multitude of different tasks. A priori, that an abductive problem may emerge in any part of the design process can be expected ${ }^{13}$.

\subsubsection{Abductive inference: property of the inference, not just a type}

In science, the main type of abduction is the inference of the cause and/or rule from effect. This represents regressive inference, reasoning backwards. Reasoning backwards is similarly a common context for abduction in design. In design parlance, the question is about moving in the direction of means in an ends-means chain.

\footnotetext{
12 However, of course information acquired from literature or colleagues may also trigger a creative abduction.

13 Dorst's (2006) critical remarks regarding the customary idea of a specific design problem providing a starting point for design emphasise this point; "If the "design problem" in general is not knowable at any specific point in the design process; and if it is evolving in the design process-at least until the creation of the design concept, and possibly beyond that point; and if the connotations of the very concepts that are used to describe a "design problem" are shifting as a part of the design effort; then we need to radically reconsider our use of the term "design problem.."”
} 
However, it is suggested that other types of inference in design may be abductive, especially transformation (of the problem) as well as decomposition (of the problem and solution) and composition (of the solution). Further, there may be manipulative abduction such as sketching (Magnani 2004). All such inferences may be abductive or non-abductive, depending on whether they create a new idea or stay in the domain of the habitual and known (in the given context).

\subsubsection{Outcome of abduction}

The outcome of a scientific abduction is a hypothetical statement about nature- "something may be". The other criterion Peirce attaches to the outcome of abduction is "uberty", fertility. In design, the outcome of abduction is a hypothetical solution candidate (conceptual or detailed, partial or total) or a design step facilitating the solution. Especially in the latter case, uberty is thus the evaluation criterion. Uberty can also be related to the strategic role (Paavola 2004) of abductive inferences in the design process. The mood of an abductive conclusion is "investigand", it points out how to continue the (tentative) process of finding a solution (Ma and Pietarinen in press.).

The result of design abduction is hypothetical in the sense that it is novel and it is not yet certain whether the move leads to a successful design. Thus the hypothesis is not about validity of a natural law or theory, but rather the utility of the outcome of the abduction as a part of the design solution or for the design process.

Additional criteria can be set to design abduction, depending on the situation. Thus, the outcome of design abduction may be abstract and general or concrete and particular. That the thing abduced is possible, doable, is an important criterion especially in embodiment design. But in other cases, the uberty of the outcome, its ability to propel the process forward and to inspire further steps, may accentuate.

\subsubsection{Cognitive/psychological character}

Peirce connects abduction to a psychological process, not dissimilar to what Poincaré has suggested for creativity. Incubation of the problem, the solution emerging in a flash (CP 5.181, 1903), and the subjectively felt certainty connected to the outcome, are the hallmarks of this description. Although such a process seems to imply an abductive inference, it is not clear whether abduction always emerges through such a process. 


\subsection{Types of abductive inference in design}

\subsubsection{Abductive regressive inference}

This is the original type of inference named by Peirce as abduction in science: regressive (backwards) inference from effects to a (hypothetical) cause. In design, the concept of regressive inference is similarly time honoured; already Aristotle (n.d.) described deliberation in the following way:

They assume the end and consider how and by what means it is to be attained; and if it seems to be produced by several means they consider by which it is most easily and best produced, while if it is achieved by one only they consider how it will be achieved by this and by what means this will be achieved, till they come to the first cause, which in the order of discovery is last.

It has been customary to call this reasoning chain the means-ends chain (Hughes 2009). Usually, neither inferences nor ends or means are characterised in any more detailed way; for example, regarding creativity.

However, as presented above, under influence by Peirce, design theorists have focused on regressive inference as abduction, starting from March (1976), with follow-up especially by Roozenburg (1993), Dorst (2011) and others. With their starting point in Peirce (rather than the traditional view on means-ends), these authors depict design abduction as one singular inference, especially from desired behaviour or function to structure. Note that this inference from behaviour to structure has usually been called synthesis in design literature; for example, by Hubka and Eder (1992) and by Gero (1999).

This single-inference view has been criticized by Kroll and Koskela (2016), who have pointed out that this should rather be a two inference chain, covering also the stage of conceptual solution. In other terms, a generalising inference creates the conceptual solution, and a particularising inference, the embodied solution.

However, it can be argued that there is in design a wider generic chain of reasoning backward and forward. For example Vermaas (2013) defines it as follows: (1) Goal of the device; (2) Action with the device; (3) Function of the device; (4) Behaviour of the device; (5) Structure of the device. Further, rarely is there one single chain of inferences in design but rather both the functions and structures have to be decomposed into their constituent parts, with their own means-ends chains. 
The regressive inferences in design show a multitude of characteristics; some are habitual, some are selective and some are creative. It is these creative regressive inferences that we call abductive. It can be asked whether abductive regressive inferences in design are located only between "behaviour and structure", as implied by the former treatments of design abduction. We contend that abductive regressive inferences may occur in all parts of the means-ends chain of design.

\subsubsection{Abductive composition}

The term composition refers here to a spatial or relational (abstract) arrangement of component parts of a system. Although Peirce's canonical definition of abduction does not explicitly capture this kind of mental move, he discussed it similarly to abduction, as something leading to a new idea ${ }^{14}$ (Peirce, CP 7.498 1898):

Suppose I have long been puzzling over some problem, - say how to construct a really good typewriter. Now there are several ideas dimly in my mind from time, none of which taken by itself has any particular analogy with my grand problem. But someday these ideas, all present in consciousness together but yet all very dim deep in the depths of subconscious thought, chance to get joined together in a particular way such that the combination does present a close analogy to my difficulty. That combination almost instantly flashes out into vividness. Now it cannot be contiguity; for the combination is altogether a new idea. It never occurred to me before; and consequently cannot be subject to any acquired habit. It must be, as it appears to be, its analogy, or resemblance in form, to the nodus of my problem which brings it into vividness. Now what can that be but pure fundamental association by resemblance?

That Peirce did not explicitly consider creative composition as abduction (in science) may be due to his focus especially on physics where causality relations accentuate as major scientific problems. Instead, in disciplines like chemistry and biology, finding the composition of an entity, the component ingredients of which are known, is a frequently encountered problem type. The characterisation of DNA as a double helix (Pray 2008) and the discovery by von Kekulé of certain organic compounds being closed chains, rings, regarding

\footnotetext{
14 Indeed, Paavola's (2004) characterization of strategic abduction approaches the understanding of abduction as composition: "This is strategic thinking: the constraints and hints that help in hypothesis finding are taken into account. And the goal in abductive inference (at least in most cases) is to find an overall pattern into which all evidence and clues fit ... and this phase especially requires that various inferential moves be put together skillfully and by taking various clues and constraints into account (a paradigmatic case is detective stories, but this is in itself a very general model)."
} 
their molecule structure (Koestler 1975), provide examples of abductive composition.

Composition has a time honoured place in literature on design and its antecedents. In rhetoric, arrangement was the second of the five canons, referring to the positioning of topics into a speech. This linear, one-dimensional, understanding of composition was already in Antiquity generalised into two-dimensional cases (painting) and threedimensional cases (sculpture, architecture). Still at the brink of the modern period, the last great scholar in rhetoric, Vico, held that ingegno (invention) gives things "a new turn or puts them into proper arrangement and relationships" (Verene 1981). The position and influence of rhetoric waned, but the idea of composition held its position, for example in architecture. In fact, the seminal author on design abduction, March (1976), named the outcome of abduction in architectural design "composition".

A vivid and illustrative example of an abductive composition is provided by the architect Aalto, who describes his working method as follows (Wilson 1979):

The large number of different demands and sub-problems form an obstacle that is difficult for the architectural concept to break through. In such cases I work - sometimes totally on instinct - in the following manner. For a moment I forget all the maze of problems. After I have developed a feel for the program and its innumerable demands have been engraved in my subconscious, I begin to draw in a manner rather like that of abstract art. Led only by my instincts I draw, not architectural syntheses, but sometimes even childish composition, and via this route I eventually arrive at an abstract basis to the main concept, a kind of universal substance with whose help the numerous quarrelling sub-problems can be brought into harmony.

The many similarities of this description to Peirce's account are noteworthy. However, there is a new element, namely turning to an external medium, sketching, as support to composition. This is another type of abduction to be discussed next.

To sum up, we define abductive composition as such a spatial or relational (abstract) arrangement of component parts of a system, which can be interpreted as a new idea in the context.

\subsubsection{Manipulative abduction}

This is not a type of abduction discussed by Peirce. Magnani (2005) characterises manipulative abduction: "In this kind of action-based abduction the suggested hypotheses are inherently ambiguous until 
articulated into configurations of real or imagined entities (images, models or concrete apparatus and instruments)." One of the most common forms of manipulative abduction in design may be sketching. According to Goldschmidt (1991), "in sketching, the designer creates visual displays which help induce images of the entity that is being designed". Kroll et al. (2001) describe a conceptual design method called "parameter analysis", in which the concepts and ideas ('parameters') proposed while designing cannot be evaluated directly; rather they have to be implemented as hardware representations ('configurations') first. The configurations themselves are only temporal and mostly serve to facilitate an evaluation.

In his book "The reflective practitioner", Schön has many examples of this type of design operation. He describes an academic supervisor in architecture (Schön 1993, 95):

Quist makes his moves in a language of designing which combines drawing and speaking.

Such moves may lead to abductive insights (Schön 1993, 102):

He discovers in the situation's back-talk a whole new idea which generates a system of implications for further moves.

The outcome may also be another type of abduction, to be discussed below, namely reframing (Schön 1993, 166):

But their on-the-spot experiments, conducted in the virtual worlds of sketch-pad or storytelling, also function as transforming moves and exploratory probes. Hypothesis testing has the limited function of enabling them to achieve satisfactory moves or to surface phenomena which cause them to reframe the situation.

\subsubsection{Abductive transformation}

Peirce (1907) discusses this type of inference in connection to Desargues' theorem in geometry. In this particular problem, the twodimensional case is best proven by seeing it as a projection of the threedimensional case. For explaining this move, Peirce introduces theorematic or theôric reasoning, which is deductive and undisputable (in contrast to the Peircean abduction that is non-deductive and hypothetical), but otherwise similar to abduction: "...theôric reasoning. It is very plainly allied to retroduction, ...". The core of theôric reasoning is "in the transformation of the problem - or its statement - due to viewing it from another point of view" (Peirce 1907). Peirce translates "theôric", coming from the Greek word for theory, as "the power of looking at facts from a novel point of view" (Peirce 1907). 
Noteworthily, Hoffman (2010) classifies theoric reasoning as one type of abduction.

However, what Peirce describes has been a well-known step, namely drawing of auxiliary figures, towards a solution in geometry already since Antiquity. Aristotle's suggestion of the similarity of deliberation (into which design arguably falls) and geometric analysis has been interpreted as covering also such transformation of the problem (Koskela et al. 2014). Unfortunately, Aristotle's design theory was hardly followed up.

In the current design literature, Schön (1993) seems to have seminally described abductive transformation (although not connecting it to abduction explicitly):

When he finds himself stuck in a problematic situation which he cannot readily convert to a manageable problem, he may construct a new way of setting the problem-a new frame which, in what I shall call a "frame experiment", he tries to impose on the situation.

Inspired by Schön, design theorists have adopted the term of frame (Dorst 2011) to refer to transformation.

An abductive transformation in design does not create a hypothetical solution, rather it creates a new problem that hypothetically is easier to solve than the original one. It is thus an example of strategic abduction (Paavola 2004).

\subsubsection{Abductive decomposition}

Decomposition ${ }^{15}$ refers to division of a whole into constituent parts. As such, this type of mental move has been known in philosophy at least

\footnotetext{
15 It may be asked whether it is necessary to discuss abductive composition and decomposition separately when they logically seem to be the two sides of one coin: the former starts from parts and creates a whole, the latter starts from a whole and creates parts. Both are applicable to the design problem and to its solution, and they often occur sequentially. A problem is often decomposed into subproblems (subfunctions) because it is easier to handle smaller problems. Once sub-solutions (solutions to sub-functions or subproblems) are found, they need to be composed into a whole solution. However, decomposition can also be applied to a solution (structure), if we need to allocate its components to different manufacturers or distinguish between parts that need to be made vs. those to purchase off-the-shelf. Likewise, composition can also be applied to functions, if we identify sub-functions that are realisable as a single entity. For example, if we need to convert electrical energy to rotational motion (realisable as an electric motor), and we need to reduce the speed of rotation (a gearbox), we may combine the two sub-functions because we recognise the possibility to use a gearmotor (a combination of motor and gearbox). Thus, the problems triggering abductive composition, on one hand, and abductive
} 
since Plato, for whom division was an important operation for defining things ${ }^{16}$. However, as far as we know neither Peirce nor later abduction scholars have related abductive insights to decomposition.

In the domain of design, decomposition is a recognized mental move, referring especially to the decomposition of functions and structures (Smith and Browne 1993). In addition, there is the important step of allocation of functions to different parts of the structure, which we subsume under the term decomposition.

Our justification for the existence of abductive decomposition is empirical. Dorst and Cross (2001) describe an experiment with experienced designers, where all took the opportunity of separating the functions of the targeted artefact, a litter bin in a train, into two parts, realising them separately when earlier approaches had ended up at one integral artefact. All designers, working alone, considered this to be a creative, new idea.

Suh's (1990) method of axiomatic design has increased interest in creative and novel decomposing by pinpointing the importance of independence in the realisation of functional requirements.

\subsubsection{Abductive analogical reasoning}

Analogical reasoning can be characterised as an inference from one particular to another particular. Thus it is opposed to conventional notions on induction, deduction and abduction, where at least one premise or conclusion is general ${ }^{17}$. In other words, it is reasoning from case to case - hence also the term case-based reasoning.

Analogies and analogical inferences have been considered as a valid way of reasoning since Antiquity (Bartha 2013). They have been commonly recognised as important elements of scientific discovery (Schickore 2014). For Peirce, an analogical inference appeared as a mixture of abduction and induction (possibly with some elements of deduction) (McJohn 1993; also see Peirce CP 5.277, 1868; CP 2.787, 1902). Commonsensically, the abductive element of an analogy is the

decomposition, on the other hand, are different and various, and it seems safe to treat them separately.

16 In more recent times, Bergson has had ideas aligning to Plato's method of collection and division (Lawlor \& Moulard Leonard 2013).

17 This way of contrasting analogy to other well-known types of reasoning, presented in ("Analogy" 2015), deserves to be justified. Of course, the very purpose of induction is to generalize. Regarding deduction, Peirce (CP 2.620,1878) states: "All deduction is of this character; it is merely the application of general rules to particular cases." And regarding abduction (Peirce CP 7.218,1901): "Abduction seeks theory". 
recognition of the similarity of the cases, whereas the projection from the one case to the other provides for the inductive element.

In the recent design literature, analogical reasoning has been analysed from many angles, and methods have been devised for supporting "design-by-analogy" (Goel 1997, McAdams and Wood 2000). The whole area of biomimicry (several other terms, like biomimetics and bionics, are also used in roughly the same meaning) is based on utilising analogies from the biological world in product design. A well-known example is provided by the type of fabric hook and loop fastener colloquially known as Velcro, the design of which was inspired by burs from the plant burdock.

The use of analogies in design takes many forms, not yet much explored in the scholarly literature:

- analogy based on form (the Velcro example)

- visual analogy (Casakin and Goldschmidt 2000)

- analogy based on common physical principles (for example, taking inspiration from maple seeds for a single-wing air vehicle (Fregene and Bolden 2010) or looking at a pendulum as a spring because both generate a restoring force when their equilibrium is disturbed (Kroll 2013)).

As a general concept, analogy has been characterised as transfer of information from a source situation to the target situation (Casakin and Goldschmidt 2000). Thus, it seems to cater to many specific design inference types with insights, such as regressive, compositional or transformational inferences. Obviously, analogies in design may be abductive, resulting in new ideas, or non-abductive. The common approach of using precedent cases known to the designer, may generally fall into the category of non-abductive analogy.

\subsubsection{Abductive invention of requirements}

The design problem, in the sense of constraints and functional requirements, is hardly ever given to the designer in its totality; rather, adding understanding of the problem is one integral part of design, usually called need analysis or task clarification. The first approaches to deal with this issue can be traced back to the ancient discipline of rhetoric, which emerged from the need to prepare - indeed design speeches for defense or accusation at a court of law. The stage of finding ingredients and arguments (called topics) for the speech was called inventio, and authorities on rhetoric, such as Aristotle and Cicero, created guidelines for this activity. The main underlying idea was that it is easier to find something if one knows where to search, and thus 
pinpointing generic places (topoi) for arguments emerged as the popular methodological approach.

As far as it is known, the issue of adding understanding on the problem has not been identified and discussed as an individual stage in science, perhaps for the simple reason that scientific research as such equates to it. Thus, it has not been discussed in terms of involved inference types, neither by Peirce nor by later scholars.

In the early design literature, the "analysis-synthesis-evaluation" model of design contained an explicit stage, analysis, for extending the understanding of the problem (Braha and Maimon 1997). Subsequently, the focus has shifted to considering analysis (in this specific sense) as an intertwined aspect of the design effort, as expressed in the slogan 18 "analysis by synthesis", made popular by Lawson (1980). The underlying idea is that hidden requirements are found through the attempt to solve the problem rather than preceding it. The same idea is also forwarded through the claim that the problem space and the solution space are co-developed in design (Maher and Poon 1996).

The capture of hidden requirements is illuminatingly described by Suwa et al. (2000):

There are at least two distinct ways in which this architect invented design issues or requirements. One way is to retrieve explicit knowledge or past cases and generate issues or requirements as the knowledge or the cases prescribe. The other way is to invent design issues or requirements by some justifications or reasons which are spontaneously constructed at the moment; those justifications or reasons are constructed on the fly by being mediated by a tacit component of the designer's knowledge.

It is the latter way that arguably is abductive. But how is abduction triggered? Through solutions attempts (Suwa et al. 2000). Note that it

\footnotetext{
18 The concept seems to originate from research on perception in the 1950s (Halle and Stevens 1959). The idea is that "speech perception involves reconstructing the production plan" (Bever and Poeppel 2010), where speech perception refers to analysis and (internal) reconstruction of the production plan of speech equates to synthesis. This mechanism has been argued to exist also in reading and visual recognition. An up-to-date description of analysis by synthesis is provided in (Poeppel et al. 2008) : "In particular, analysis-by-synthesis, or perception driven by predictive coding based on internal forward models, is a decidedly active stance towards perception that has been characterized as a 'hypothesize-and-test' approach. A minimal amount of signal triggers internal guesses about the perceptual target representation; the guesses (hypotheses) are recoded, or synthesized, into a format that permits comparison with the input signal." This understanding of analysis by synthesis seems to be applicable also to the use of this approach in design.
} 
is not only requirements relating to the original design problem but also conflicts between different design elements that get retrieved in this way:

The architect's encounter of unintended visuo-spatial features in his sketches somehow activated parts of the tacit component of his knowledge, and thus the resulting interaction between the parts of the tacit knowledge and the unintended visuo-spatial features led to the construction of justifications or reasons for an inventive idea.

Abductive invention of requirements leads to unexpected findings, and there is no well-articulated problem preceding it, only the diffuse understanding about incompleteness of the requirements at hand. Research relates this type of abduction to sketching but it has to be noted that sketching also operates in and expands the solution space, having thus a wider scope.

\subsubsection{Other forms of abduction in design}

The preceding discussion on types of abduction in design is by no means exhaustive. There are rarer types of abduction that cannot be discussed in detail due to space limitations. Two examples will suffice for illustration.

Abduction for integrating scientific theories in design has been discussed by Tomiyama et al. (2003), using the integration of knowledge on cooling and access in refrigerator design as an illustrative case. They identify it as second order existential abduction in Schurz' (2008) classification. In turn, the 1977 design of the Gossamer Condor, the first human-powered aircraft capable of sustained flight, was inspired by manipulating the equation representing the forces affecting an aircraft into such a form that emphasises what should be prioritised as design targets, especially a long wing span, low weight and low speed (Kroll and Farbman, 2016). In the mentioned Schurz' classification, this arguably represents theoretical model abduction.

\section{Conclusion}

By focusing on the differences between science and design as well as on empirical knowledge of different phenomena comprising design, we have derived new conceptions of abduction in design. Similarly to seminal and many subsequent treatments of abduction in science, we hold that an abductive design insight leads to a new idea, still hypothetical, by means of often subconscious, uncontrolled mental 
processes (implying thus an incubation period and often the flash of insight when it surfaces to the consciousness).

However, given the differences of context, abduction in design shows characteristics not found (or at least not identified clearly up to now) in science. Design abduction may emerge in any part of the design process (not just in the beginning as in typical reconstructions on science). Abduction can occur in connection to practically all inference types in design (rather than just through regressive inferences as in typical formulations of science); it is a property of an inference besides an inference itself. Abduction usually leads to an idea new in the context (rather than to entirely new ideas as in science). The main criterion of an abduced insight in design is its utility (rather than showing its truth as in typical examples of science).

What is the importance of these new conceptions of abduction for the design domain? For the first time, the different mental moves, which lead to new ideas in design, have been at least initially identified and described. The new conceptions invite empirical validation and verification. Based on this description, hopefully gaining validity but also perhaps evolving, new prescriptions for creative design may be devised in the future. Especially, the different categories of abduction might serve as places (topoi) in which to search for novel solution ideas when facing a design task, similar to existing creativity techniques but at a higher level of abstraction. Empirical research could then be applied to better understand the process of discovery within design and offer new insights on different forms or kinds of creativity. Generally speaking, expanded understanding on abduction offers new means and models to discuss and teach various phenomena in design.

However, we also humbly offer an unintended side outcome for the philosophy of science. The rich variety of abductive inferences found in design easily creates the suspicion that Peirce's seminal discussion on abduction in science has been interpreted in too schematic and narrow a way, failing to capture types of abduction not following the canonical form of "given the result, find the rule and the cause". The question arises whether an overhaul of the conception of abduction is also needed on the side of science.

\section{Acknowledgement}

The authors are grateful for the insightful comments and helpful suggestions by the editors and by Dr. Glenn Ballard. 


\section{References}

Aliseda, A. (2006). Abductive Reasoning. Logical Investigations into Discovery and Explanation. Synthese Library, vol. 330. Dordrect: Springer.

Analogy. (2015, November 15). In Wikipedia, The Free Encyclopedia. Retrieved on November 28, 2015, from https://en.wikipedia.org/w/index.php?title=Analogy\&oldid=6908 22710

Aristotle (n.d.) Nicomachean ethics [electronic resource]. http://classics.mit.edu/Aristotle/nicomachaen.html

Bartha, P. (2013). Analogy and analogical reasoning. The Stanford Encyclopedia of Philosophy. http://plato.stanford.edu/archives/fall2013/entries/reasoninganalogy/. Accessed 11 December 2015.

Bever, T.G., \& Poeppel, D. (2010). Analysis by synthesis: a (re-) emerging program of research for language and vision. Biolinguistics, 4(2-3), 174-200.

Boden, M.A. (1996). Dimensions of creativity. Cambridge, MA: MIT Press.

Braha, D., \& Maimon, O. (1997). The design process: properties, paradigms, and structure. IEEE Transactions on Systems, Man and Cybernetics, Part A: Systems and Humans, 27(2), 146-166.

Casakin, H.P., \& Goldschmidt, G. (2000). Reasoning by visual analogy in design problem-solving: the role of guidance. Environment and Planning B: Planning and Design, 27, 105-119.

Chen, Y., Zhang, Z., Xie, Y., Zhao, M. (2015a). A new model of conceptual design based on Scientific Ontology and intentionality theory. Part I: the conceptual foundation. Design Studies, 37, 12-36.

Chen, Y., Zhao, M., Xie, Y., Zhang, Z. (2015b). A new model of conceptual design based on Scientific Ontology and intentionality theory. Part II: the process model. Design Studies, 38, 139-160.

Cramer-Petersen, C.L., \& Ahmed-Kristensen, S, (2015), Reasoning in design: idea generation condition effects on reasoning processes and evaluation of ideas. Proceedings of the 22nd Innovation and Product Development Management Conference, June 14-16, Copenhagen, European Institute for Advanced Studies in Management (EIASM).

Dorst, K. (2006). Design problems and design paradoxes. Design Issues, 22(3), 4-17.

Dorst, K. (2011) The core of 'design thinking' and its application. Design Studies, 32, 521-532.

Dorst, K., \& Cross, N. (2001). Creativity in the design process: coevolution of problem-solution. Design studies, 22(5), 425-437. 
Dunne, D. D., \& Dougherty, D. (2016). Abductive reasoning: how innovators navigate in the labyrinth of complex product innovation. Organization Studies, 37(2), 131-159.

Eco, U. (1983) Horns, hooves, insteps: some hypotheses on three types of abduction. In U. Eco \& T. A. Sebeok (Eds.), The sign of three. Dupin, Holmes, Peirce (pp. 198-220). Bloomington: Indiana University Press.

Eco, U., \& Sebeok, T. A. (Eds.) (1983). The sign of three. Dupin, Holmes, Peirce. Bloomington: Indiana University Press.

Eekels, J., \& Roozenburg, N. F. (1991). A methodological comparison of the structures of scientific research and engineering design: their similarities and differences. Design Studies, 12(4), 197-203.

Fann, K. T. (1970). Peirce's theory of abduction. The Hague: Martinus Nijhoff.

Feibleman, J.K. (1969) An introduction to the philosophy of Charles $S$. Peirce: interpreted as a system. Cambridge (MA): M.I.T. Press.

Flórez, J. A. (2014). Peirce's Theory of the Origin of Abduction in Aristotle. Transactions of the Charles S. Peirce Society: A Quarterly Journal in American Philosophy, 50(2), 265-280.

Fregene, K., \& Bolden, C. L. (2010). Dynamics and control of a biomimetic single-wing nano air vehicle. Proceedings of IEEE American Control Conference (ACC), pp. 51-56.

Gabbay, D. M., Thagard, P., Woods, J., Meijers, A. W. (2009). Philosophy of technology and engineering sciences. Burlington, MA: Elsevier.

Gabbay, D. M. \& Woods, J. (2005). The reach of abduction. Insight and trial. A practical logic of cognitive systems. Volume 2. Amsterdam: Elsevier.

Goldschmidt, G. (1991). The dialectics of sketching. Creativity research journal, 4(2), 123-143.

Smith, G. F., \& Browne, G. J. (1993). Conceptual foundations of design problem solving. IEEE Transactions on Systems, Man and Cybernetics, 23(5), 1209-1219.

Gero, J. S. (1999). Constructive memory in design thinking. In Design Thinking Research Symposium: Design Representation (pp. 29-35). MIT, Cambridge.

Goel, A. K. (1997). Design, analogy, and creativity. IEEE expert, 12(3), 62-70.

Goel, V. (1988). Complicating the 'logic of design'. Design Studies, 9(4), 229-234.Habermas, J. (1978). Knowledge and human interests. 2nd ed., pp. 147-148, London: Heinemann.

Halle, M., \& Stevens, K. (1959). Analysis by synthesis. In W. Wathen Dunn \& L. E. Woods (Eds.), Proceeding of the Seminar on Speech Compression and Processing, Vol. II, paper D7.

Hanson, N. R. (1958). Patterns of discovery. Cambridge: Cambridge University Press. 
Harman, G. H. (1965). The inference to the best explanation. The Philosophical Review, 74(1), 88-95.

Harman, G. (1968). Knowledge, inference, and explanation. American Philosophical Quarterly, 5(3), 164-173.

Hintikka, J. (1999). What is abduction? The fundamental problem of contemporary epistemology. In Inquiry as inquiry: A logic of scientific discovery (pp. 91-113). Netherlands: Springer.

Hintikka, J. (2007). Socratic epistemology: Explorations of knowledgeseeking by questioning. Cambridge: Cambridge University Press.

Hintikka, J., \& Remes, U. (1974). The method of analysis: its geometrical origin and its general significance. Boston: D. Reidel.

Hoffmann, M. H. (2010). "Theoric Transformations" and a new classification of abductive inferences. Transactions of the Charles $S$. Peirce Society: A Quarterly Journal in American Philosophy, 46(4), 570-590.

Hubka, V., \& Eder, W. E. (1992). Engineering design. Zürich: Heurista.

Hughes, J. (2009). Practical reasoning and engineering. In: Philosophy of technology and engineering sciences, ed. Dov M Gabbay, Anthonie Meijers, Paul Thagard, and John Woods, 375-402.

Koestler, A. (1975). The act of creation. London: Picador.

Kolko, J. (2010). Abductive thinking and sensemaking: the drivers of design synthesis. Design Issues, 26, 15-28.

Koskela, L., Codinhoto, R., Tzortzopoulos, P. \& Kagioglou, M. (2014). The Aristotelian Proto-Theory of Design. In: Chakrabarti, A., \& Blessing, L.T.M. (Eds.), An Anthology of Theories and Models of Design: Philosophy, Approaches and Empirical Explorations. London: Springer, 285-304.

Kroll, E. (2013). Design theory and conceptual design: contrasting functional decomposition and morphology with parameter analysis. Research in Engineering Design, 24(2), 165-183.

Kroll, E., \& Farbman, I. (2016). Casting innovative aerospace design case studies in the parameter analysis framework to uncover the design process of experts. Design Science, 2(e2).

Kroll, E., \& Koskela, L. (2016). Explicating concepts in reasoning from function to form by two-step innovative abductions. Artificial Intelligence for Engineering Design, Analysis and Manufacturing (AIEDAM), 30, 125-137.

Kroll, E., Condoor, S. S., Jansson, D. G. (2001) Innovative conceptual design: theory and application of parameter analysis. Cambridge: Cambridge University Press.

Lagerlund, H. (2016) Medieval Theories of the Syllogism, The Stanford Encyclopedia of Philosophy (Spring 2016 Edition), Edward N. Zalta (ed.), URL = <http://plato.stanford.edu/archives/spr2016/entries/medievalsyllogism/>. Accesses 20 April 2016 
Lawlor, L. \& Moulard Leonard, V. (2013) Henri Bergson, The Stanford Encyclopedia of Philosophy (Winter 2013 Edition), Edward N. Zalta (ed.), URL <http://plato.stanford.edu/archives/win2013/entries/bergson/>. Accessed 20 December 2015

Lawson, B. (1980). How designers think. London: Architectural Press.

Lu, C.-Y., \& Liu, A. (2012). Abductive reasoning for design synthesis. CIRP Annals - Manufacturing Technology, 61, 143-146.

Ma, M., \& Pietarinen, A. V. (2016) A Dynamic Approach to Peirce's Interrogative Construal of Abductive Logic. IfCoLog Journal of Logics and their Applications, 3(3), 73-104.

Magnani, L. (2001). Abduction, reason, and science. Processes of discovery and explanation. New York: Kluwer Academic/Plenum.

Magnani, L. (2004). Model-based and manipulative abduction in science. Foundations of science, 9(3), 219-247.

Magnani, L. (2005). Inductive generalizations and manipulative abduction. Department of Philosophy and Computational Philosophy Laboratory, University of Pavia. http://www.cs.bris.ac.uk/ oray/AIAI05/paper_magnani.pdf. Accessed 11 December 2015.

Maher, M. L., \& Poon, J. (1996). Modeling design exploration as coevolution. Computer-Aided Civil and Infrastructure Engineering, 11(3), 195-209.

March, L. (1976). The logic of design and the question of value. In L. March (Ed.), The architecture of form (pp. 1-40). Cambridge: Cambridge University Press.

McAdams, D. A., \& Wood, K. L. (2000). Quantitative measures for design by analogy. Proceedings of ASME Design Engineering Technical Conferences (DETC'00), September 10-13, Baltimore.

McJohn, S. M. (1993). On uberty: legal reasoning by analogy and Peirce's theory of abduction. Willamette Law Review, 29, 191-235.

Minnameier, G. (2004). Peirce-suit of truth - Why inference to the best explanation and abduction ought not to be confused. Erkenntnis 60: 75-105.

Newton I. (2003) Opticks. (Great Mind Series), Prometheus Books.

Nickles, T. (Ed.) (1980). Scientific discovery, logic, and rationality. Dordrecht: D. Reidel.

Niiniluoto, I. (1999a). Defending abduction. Philosophy of science, S436S451.

Niiniluoto, I. (1999b). Abduction and geometrical analysis. Notes on Charles S. Peirce and Edgar Allan Poe. In L. Magnani et al. (Eds.), Model-based reasoning in scientific discovery. New York: Kluwer Academic/Plenum.

Paavola, S. (2004). Abduction as a logic and methodology of discovery: The importance of strategies. Foundations of Science, 9(3), 267-283. 
Paavola, S. (2006). Hansonian and Harmanian abduction as models of discovery. International Studies in the Philosophy of Science, 20(1), 93-108.

Paavola, S. (2012). On the origin of ideas. An abductivist approach to discovery. Revised and enlarged edition of a dissertation (2006). Saarbrücken: Lap Lambert Academic Publishing.

Paavola, S., \& Hakkarainen, K. (2005). Three abductive solutions to the Meno Paradox - with instinct, inference, and distributed cognition. Studies in Philosophy and Education, 24(3-4): 235-253.

Pauwels, P., \& Bod, R. (2014). Architectural design thinking as a form of model-based reasoning. In L. Magnani (ed.), Model-Based Reasoning in Science and Technology, Studies in Applied Philosophy, Epistemology and Rational Ethics 8, Berlin: Springer-Verlag.

Peckhaus, V. (2002). Regressive analysis. Philosophiegeschichte und logische Analyse (Logical Analysis and History of Philosophy), Vol. 5, 97-110.

Peirce, Charles S. [CP (volume.paragraph, year] (1931-1958) Collected Papers of Charles Sanders Peirce, vols. 1-6, Hartshorne, C. and Weiss, P., (eds.), vols. 7-8, Burks, A. W., (ed.). Cambridge, Mass: Harvard University Press.

Peirce, Charles S. [EP (volume: page numbers, year)] (1992-8) The Essential Peirce: Selected Philosophical Writings, 2 vols., the Peirce Edition Project (eds). Bloomington \& Indianapolis: Indiana University Press.

Peirce, Charles S. [PPM (page numbers, year)] (1997) Pragmatism as a Principle and Method of Right Thinking. The 1903 Harvard Lectures on Pragmatism, Ann Turrisi (ed.). Albany: State University of New York Press.

Peirce, Charles S. [W (volume: page numbers, year)] (1982-) Writings of Charles S. Peirce: A Chronological Edition, 6 vols. (to date), the Peirce Edition Project (eds). Bloomington: Indiana University Press.

Pietarinen, A. V. J. (2014). The science to save us from philosophy of science. Axiomathes, 1-18.

Poeppel, D., Idsardi, W. J., van Wassenhove, V. (2008). Speech perception at the interface of neurobiology and linguistics. Philosophical Transactions of the Royal Society B: Biological Sciences, 363(1493), 1071-1086.

Pray, L. (2008) Discovery of DNA structure and function: Watson and Crick. Nature Education 1(1):100.

Psillos, S. (2009). An explorer upon untrodden ground: Peirce on abduction. Handbook of the history of logic: Inductive logic, 10, 117151.

Reichenbach, H. (1938) Experience and Prediction. Chicago: University of Chicago Press.

Roozenburg N. F. M. (1993). On the pattern of reasoning in innovative design. Design Studies, 14, 4-18. 
Roozenburg, N. F. M., \& Eekels, J. (1995). Product design: fundamentals and methods. Chapter 4. Chichester: John Wiley \& Sons.

Schickore, J. (2014). Scientific discovery. The Stanford Encyclopedia of Philosophy.

http://plato.stanford.edu/archives/spr2014/entries/scientificdiscovery/. Accessed 11 December 2015.

Schön, D. A. (1993). The reflective practitioner: How professionals think in action. New York: Basic Books.

Schurz, G. (2008). Patterns of abduction. Synthese, 164(2), 201-234.

Snyder, L. J. (1997). Discoverers' induction. Philosophy of Science, 64(4), 580-604.

Suh, N. P. (1990). The principles of design. New York: Oxford University Press.

Suwa, M., Gero, J., Purcell, T. (2000). Unexpected discoveries and Sinvention of design requirements: important vehicles for a design process. Design Studies, 21(6), 539-567.

Takeda, H. (1994). Abduction for design. In J. S. Gero, \& E., Tyugu (Eds.) Formal design methods for CAD (pp. 221-244). Amsterdam: NorthHolland.

Takeda, H., Sasaki, H., Nomaguchi, Y., Yoshioka, M., Shimomura, Y., Tomiyama, T. (2003). Universal abduction studio-proposal of a design support environment for creative thinking in design. Proceedings of the 14th Int. Conf. Engineering Design (ICED 03), Stockholm, Aug. 19-21.

Takeda, H., Veerkamp, P., Tomiyama, T., Yoshikawa, H. (1990). Modeling design processes. AI Magazine, 11(4), 37-48.

Thompson, K. R., Hochwarter, W. A., \& Mathys, N. J. (1997). Stretch targets: What makes them effective?. The Academy of Management Executive, 11(3), 48-60.

Tomiyama, T., Takeda, H., Yoshioka, M., Shimomura, Y. (2003). Abduction for creative design. Proceedings of ASME Design Engineering Technical Conferences (DETC'03), pp. 543-552, September 2-6, Chicago.

Ullah, A. M. M. S., Rashid, M.M., Tamaki, J. (2012). On some unique features of $\mathrm{C}-\mathrm{K}$ theory of design. CIRP Journal of Manufacturing Science and Technology, 5, 55-66.

Velázquez-Quesada, F. R., Soler-Toscano, F., Nepomuceno-Fernández, Á. (2013). An epistemic and dynamic approach to abductive reasoning: Abductive problem and abductive solution. Journal of Applied Logic, 11(4), 505-522.

Verene, D. P. (1981). Vico's science of imagination. London: Cornell University Press.

Verene, D. P. (2008). The history of philosophy: A reader's guide. Evanston: Northwestern University Press.

Vermaas, P. E. (2013). The coexistence of engineering meanings of function: four responses and their methodological implications. 
Artificial Intelligence for Engineering Design, Analysis and Manufacturing, 27(3), 191-202.

Wilson, C. S. J. (1979). Alvar Aalto and the state of modernism. International Architect, 1(2), 27-32. 